\title{
Hybrid subtractive-additive manufacturing processes for high value-added metal components
}

\author{
Panagiotis Stavropoulos $^{1} \cdot$ Harry Bikas $^{1} \cdot$ Oliver Avram $^{2} \cdot$ Anna Valente $^{2} \cdot$ George Chryssolouris $^{1}$
}

Received: 3 May 2020 / Accepted: 14 September 2020 / Published online: 2 October 2020

(C) The Author(s) 2020

\begin{abstract}
Hybrid process chains lack structured decision-making tools to support advanced manufacturing strategies, consisting of a simulation-enhanced sequencing and planning of additive and subtractive processes. The paper sets out a method aiming at identifying an optimal process window for additive manufacturing, while considering its integration with conventional technologies, starting from part inspection as a built-in functionality, quantifying geometrical and dimensional part deviations, and triggering an effective hybrid process recipe. The method is demonstrated on a hybrid manufacturing scenario, by dynamically sequencing laser deposition (DLM) and subtraction (milling), triggered by intermediate inspection steps to ensure consistent growth of a part.
\end{abstract}

Keywords Additive manufacturing $\cdot$ Modelling $\cdot$ Hybrid process chain

\section{Introduction}

The successful implementation of a newly designed component in the manufacturing chain and the generation of a suitable process plan is a highly complex task, which requires significant human expertise. As a result, the development of structured approaches and decision-making tools, which will help in the creation of optimized and consistent process plans [1] is a major research topic in the manufacturing industry. During the last decade, novel manufacturing technologies are rapidly emerging and establishing their position in the manufacturing sector. Their emergence is accompanied by the need to create tools and support systems, which will allow for the maximum exploitation of their potential in manufacturing applications, while reducing the necessity for human expertise and increasing the automation levels in the process planning stage [2]. Direct laser melting (DLM) is gaining interest in the manufacturing value chain as one of the key

Panagiotis Stavropoulos pstavr@1ms.mech.upatras.gr

1 Laboratory for Manufacturing Systems and Automation, Department of Mechanical Engineering and Aeronautics, University of Patras, 26504 Patras, Greece

2 SUPSI, Institute of Systems and Technologies for Sustainable Production, Galleria 2, 6928, Manno, Switzerland enablers to enhance life-to-value [3] of critical metal components [4] since it can offer very high design flexibility by enabling engineers to implement highly complex internal and external geometries and integrated functionalities on a product [5], as well as design multi-material components [6]. Whereas it may seem like a poor choice for specific applications such as the manufacturing of large components, DLM presents major opportunities - in terms of product features and process cost-effectiveness - if integrated with other technologies [7]. Examples include depositing complex features on the top of pre-existing components-either new workpieces or ones to be repaired [8] — as well as having DLM integrated into a complex process chain where also subtraction technologies are envisaged $[9,10]$. The integration of these two technologies in a hybrid process chain presents a high potential of surpassing conventional manufacturing technologies, being able to deliver products of net or near-net shape in lower production time [11]. However, although the integration of additive and subtractive processes in a single, hybrid manufacturing machine tool presents a very high level of opportunities for industrial implementation, it is still associated with very significant challenges, mainly in terms of equipment integration, process recipe design and knowledge, and process management [12]. Regarding the two latter, the main challenges are associated with determining the combination of additive and subtractive operations, which will exploit the merits of both processes in an optimal manner, and provide 
components with higher performance in terms of economical, quality, and environmental KPIs.

\section{Literature review}

Existing literature addresses the aforementioned challenges primarily from the economical perspective in order to prove the benefits of additive manufacturing in such manufacturing contexts. Kopf et al. [13] proposed a two-step methodology for equipment and process cost optimization in DLM. ElMaraghy et al. [14] have introduced a process planning algorithm, which can be utilized for cost minimization among different variants of the same product, by decomposing product features and exploiting hybrid manufacturing technologies. Priarone et al. [15] have proposed a modelling framework for the assessment of hybrid manufacturing applicability, using WAAM and machining, over conventional subtractive processes, and the benefit in terms of cost, cycle time, energy consumption, and environmental impact. Basinger et al. [16] have proposed a feature-based process planning method, aiming to create semi-automatic and automatic operation sequencing plans for hybrid manufacturing processes, focusing on the reduction of manufacturing time. In the same principle, Liu et al. [17] have developed an operation sequencing algorithm for five-axis hybrid manufacturing of complex parts, taking into account tool accessibility and focusing on the reduction of the necessary tool changes. From a technical perspective, the core challenge that is still untouched lies in the overall process design and planning and the related articulated software infrastructure enabling a complex multi-tech process engineering, deployment, and adaptation while ensuring the overall final product quality [18]. There are existing approaches [19] and platforms that allow for hybrid process planning. Behandish et al. [20] have introduced computational algorithms for path planning in hybrid manufacturing, taking also into account the manufacturability constraints of the processes involved. Luo et al. [21] have proposed a cutter selection algorithm for hybrid manufacturing, incorporating rapid pattern manufacturing (RPM) and milling. Zhu et al. [22] have proposed an algorithm, with the aim to aid in process planning and decision making in hybrid manufacturing, focusing on material consumption and process time. However, the algorithm was limited to non-metallic part manufacturing. Even at a commercial level, CAPP platforms, such as Siemens NX [23], are providing the ability to plan both additive and subtractive processes in a single tool. However, they are allowing the user to just plan the two processes successively, without providing the ability to plan them synergistically so that one can compensate for the drawbacks of the other. Moreover, limited insight is provided to the user regarding the process capabilities and how the two processes can be planned more effectively to address in the most optimal manner the product- specific KPIs. Such activities are in fact still manually run by highly skilled operators on the basis of empirical knowledge gained on the very specific equipment [1] and demand extensive effort when geometries, dimensions, and materials start to change [24].

The goal of this paper is to introduce a process planning approach, which, apart from aiding the automation of operation sequencing in a hybrid manufacturing process, will provide a holistic tool for hybrid manufacturing planning. This tool, driven by the authors experience on additive [18] and subtractive $[25,26]$ process optimization, will fill the gap of the existing process planning platforms, by accounting for part quality KPIs and introducing optimal process windows, upon which the process plan is going to be built.

The paper aims to support hybrid process chain design, engineering, and validation that can suit any machine(s) configuration running DLM together with machining operations, assisted by in-line geometrical inspection. The proposed platform is conceived to be potentially extended to other families of hybrid manufacturing technologies.

\section{Approach}

The framework for hybrid technologies addresses the life-tovalue optimization driver; this implies optimizing the process engineering in order to enhance the component performance over a fixed time horizon or ensuring specific performance targets over the longer time frame. The current work focuses on the process-related challenges and the best exploitation of multiple technologies to ensure the matching of product quality KPIs.

The proposed approach has two major innovative aspects compared with the state-of-art hybrid approaches for process planning [8]. The first one deals with the capability to generate several solutions of process plan over time, considering multiple technologies and having the master process plan (master part program on the machines) adapted based on in-line geometrical inspection (e.g. adapting some process steps based on anomalous growth of the material). The second aspect focuses on having the simulation and validation of the deposition and subtraction/machining processes integrated into the process planning phase in order to capture the physics of the process where the part quality KPIs can be appreciated. The best process recipe-formulated as a sequence of process steps and process-specific parameters - is the one leading to maximizing the selected KPIs (e.g. technical, economic, and environmental).

The proposed framework for life-to-value product optimization consists of three stages, where each stage will deploy a specific workflow in order to provide an adapted input for the subsequent ones, as presented in Fig. 1. 


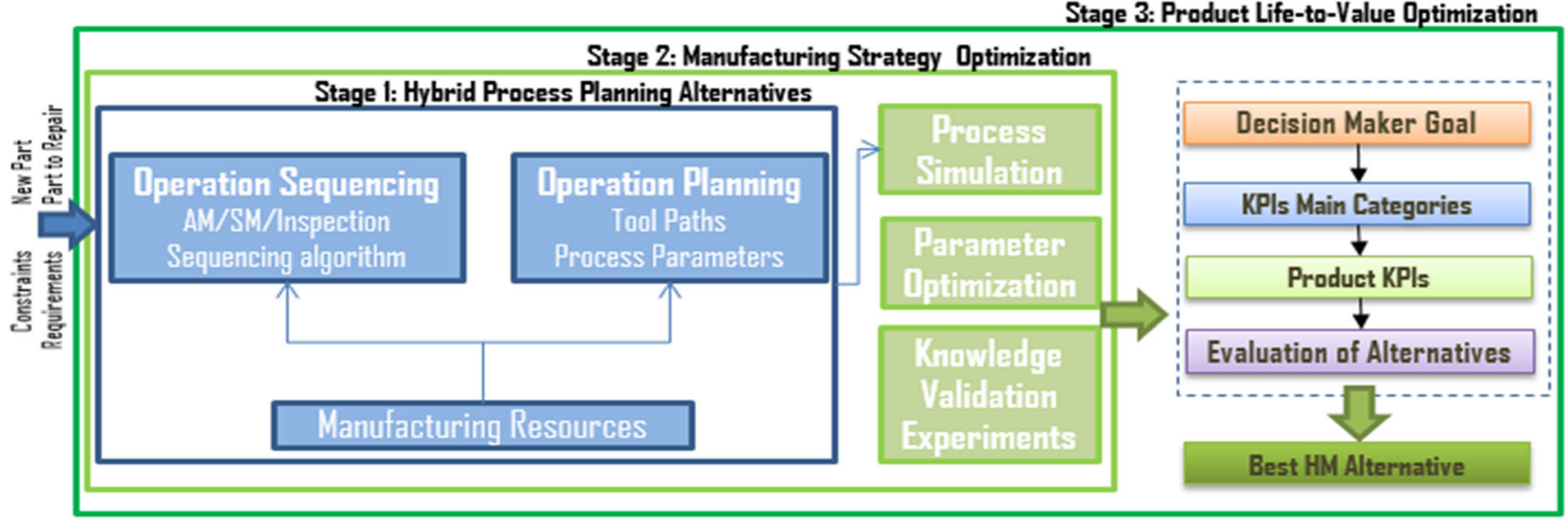

Fig. 1 Overall framework

The first stage targets the generation of hybrid process planning alternatives adapted for specific manufacturing jobs according to the user's input, such as part scenario manufacturing constraints. It mainly consists of two distinct activities, namely the operation sequencing and operation planning. The former considers three main categories of operations (i.e. additive, inspection, and subtractive), the user input as well as information about the manufacturing resources in order to derive process plans with adapted sequences. The latter aims at the selection of the initial set of process parameters and tool path strategies for the operations considered.

The second stage addresses the adaptation of the initial process parameters based on the modelling and simulation of additive and subtractive operations. This relies upon numerical modelling strategies, considerations, and results as well as validation techniques using experimental data with the scope of avoiding undesired defects and enhancing process reliability and part quality during manufacturing. The previously generated process plan alternatives provide the initial conditions from which the user of the platform can selectively decide which parameters/aspects to optimize based on its own preferences and available tools and techniques.

Various metrics, such as surface roughness, residual stress, and dimensional accuracy, and statistics, such as tool path length and cycle time, captured across the first two stages can be translated into a number of KPIs to be used for the selection of the best process plan in the third stage.

In the third stage, the user is given the possibility to systematize the evaluation of the process planning alternatives through the multi-criteria analysis capability of the framework. High-value manufacturing, considered as the application of leading-edge technical knowledge and expertise to the creation of products, processes, and associated services can foster competitive advantage, sustainable growth, and high economic value. In this respect, hybrid manufacturing has made early adopters of the technology very optimistic about the technology's prospects. Nevertheless, a structured approach is required to make informed decisions, especially in the manufacturing landscape where such decisions are never single-purpose driven.

Three main pillars (i.e. technical, economic, environmental) are used as the upper-level KPI categories to provide the decision-maker with the possibility to perform not only a product-process quality-oriented performance assessment but also a holistic evaluation of the manufacturing alternatives which eventually will translate into a life-to-value performance score for each one of them. The methodological foundation of the multi-criteria decision analysis is the Analytical Hierarchy Process (AHP) which can support complex decisions through a direct comparison between alternatives [27]. The third stage of the platform essentially breaks a complex decision into explicit goals, alternatives, and criteria (i.e. KPIs), according to the decision maker's understanding of the problem. The proposed AHP method is essentially based on three main operations: KPI's hierarchy construction, KPI's prioritization, and consistency verification.

\subsection{Stage 1: Hybrid process planning alternatives}

A unified approach in hybrid manufacturing requires a method to determine the sequence between additive, subtractive and inspection operations, generating process planning alternatives. These alternatives are formulated as a combination of (i) different operation sequences and (ii) different initial process parameters for each involved operation, taking into account the presence of the others. The method used to sequence the operations is outlined in Fig. 2.

The starting point could refer to the repair of a component, the deposition of complex features on the pre-existing part(s), or building a part from scratch. A number of alternatives can be generated, based on the combination of additive, subtractive, and inspection operations. Inspection can be used to adaptively trigger additive or subtractive operations to correct geometric deviations. Besides operation sequencing, each 


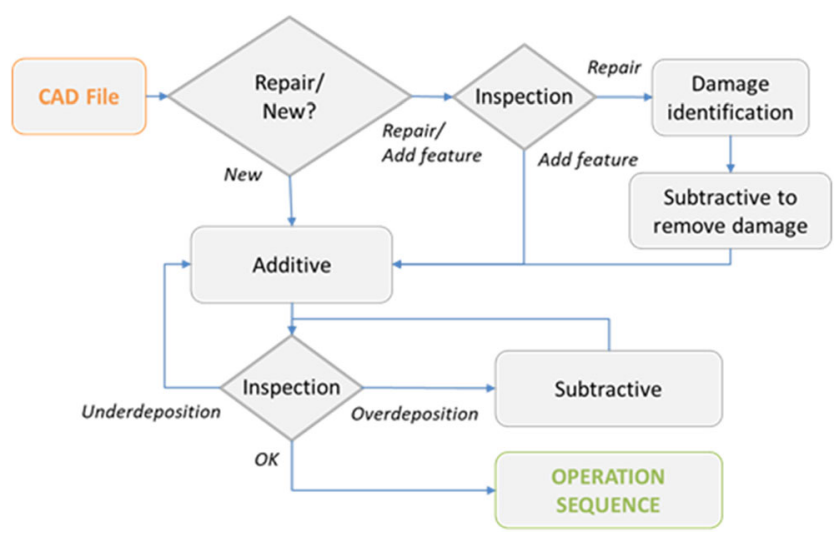

Fig. 2 Flow chart of the operation sequencing algorithm

operation may deploy a different set of process parameters, generating a number of alternative process plans which have the capability to produce the exact same part; however, the performance of each of the alternatives may differ. Figure 3 depicts the methodology that is followed during the first stage of the generation of the hybrid process plan.

\section{Stage 2: Manufacturing strategy optimization}

In order to optimize the parameters for both the DLM and milling processes involved in the proposed hybrid chain, interlinked simulation tools have been implemented, interacting with each other in an iterative way (Fig. 4). To successfully model a laser-based AM process two main aspects have to be considered: the interaction between the laser beam and the material that is deposited, as well as the phase change that the material is subjected to, during the deposition process [28]. Simulation of the DLM process involves 2 discreet steps, each one feeding data to the next. An existing mathematical model of DLM [29] has been enhanced by integrating the modelling of multiple powder ejection nozzles; the simulation tool assesses the effects of process parameter effects on deposition rate by considering interactions between the powder particles streams and mix rate, the laser beam, and the melt pool. The laser power reaching the surface of the workpiece is estimated and, assuming this power is used to re-melt the substrate with the clad having been pre-deposited, the melt-pool shape is computed using a three-dimensional analytical model. This numerical tool is coupled with a CFD simulation that allows evaluation of the effects of the powder delivery system process parameters in the powder stream characteristics, and subsequently on the DLM process. The CFD simulation consists of two successive steps: first, a simulation of the gas flow and second, a simulation of the powder particles injection using a discrete phase model (DPM). Here, key settings are the carrier and assist gas flow rates, powder flow rate, standoff distance, and nozzle angle. The CFD process simulation returns, as a result, the powder stream characteristics (dispersion angle, gas stream velocity, powder particle velocity, particle location and distribution on the deposition plate), are fed back to the numerical process model. The final output KPIs of the DLM model are the deposition rate, scanning speed, and powder efficiency. The DLM model results have been validated against the experimental results from [18].

Regarding milling modelling, the two main methodologies that are utilized are finite element modelling (FEM) based and the mechanics of cutting based models [30]. In this work, a

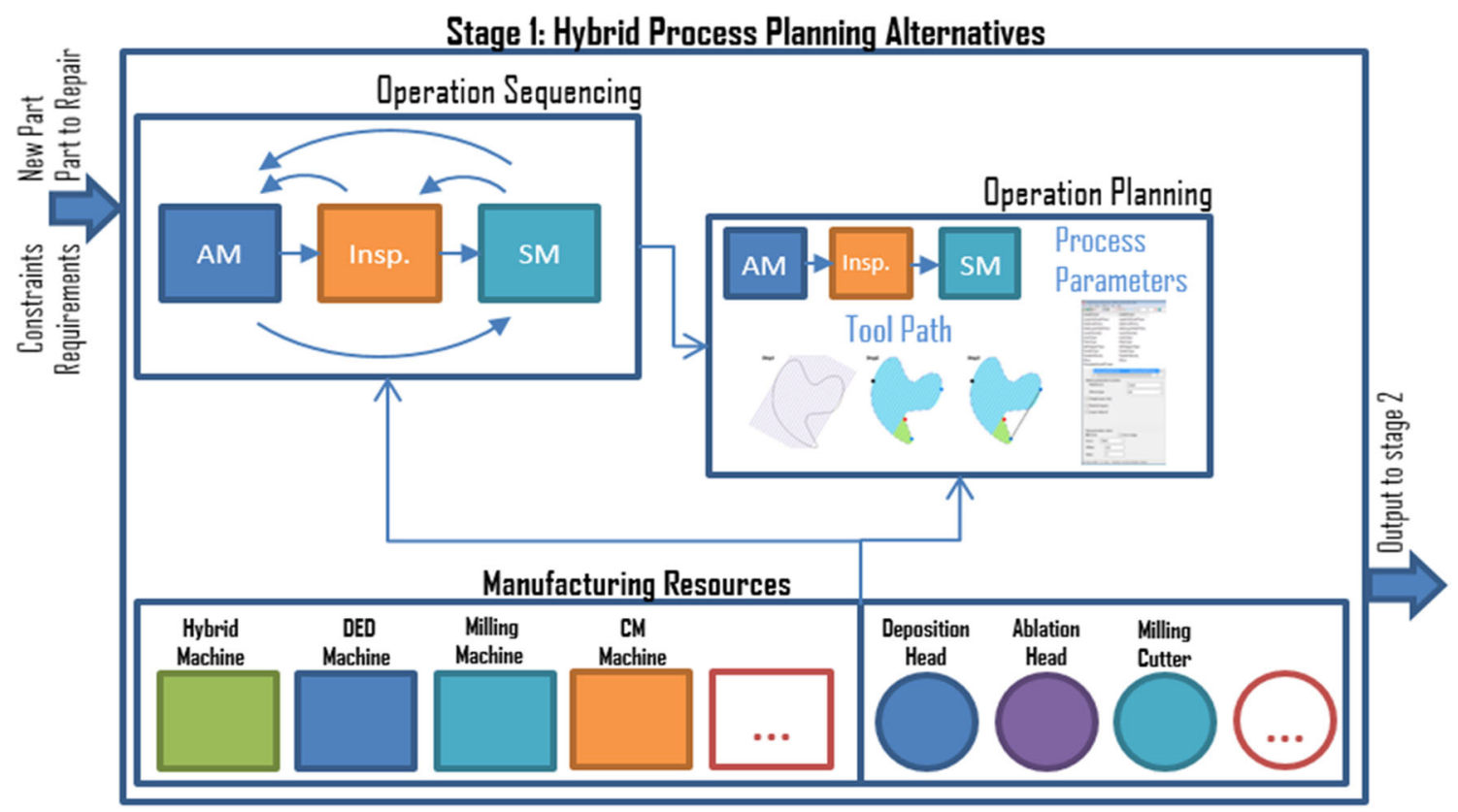

Fig. 3 Stage 1 methodology 


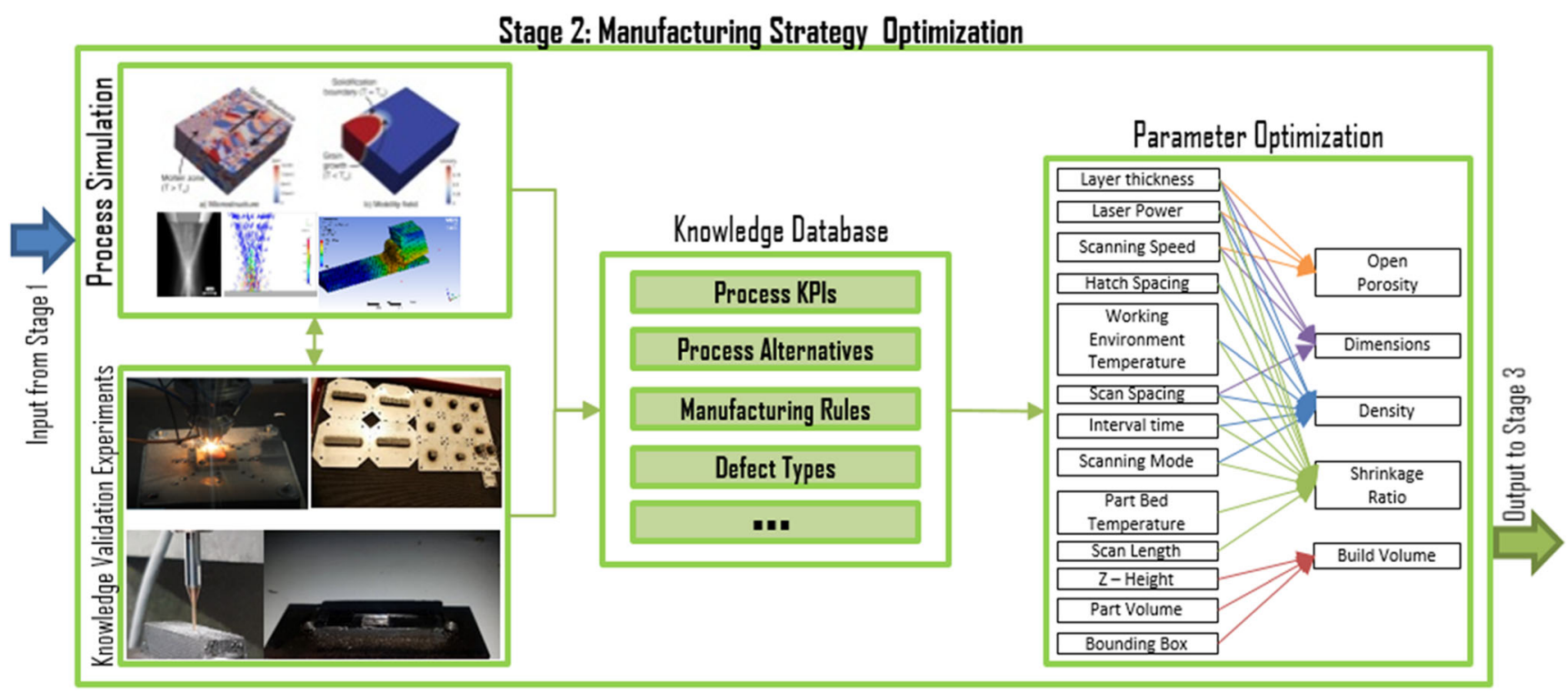

Fig. 4 Stage 2 methodology

FEM-based model is implemented, using an explicit solver and coupled Eulerian-Lagrangian (CEL) mesh to compensate for the extremely high strain rates (up to $\dot{\varepsilon}=10^{6} \mathrm{~s}^{-1}$ ) and large deformations of the process, using Johnson-Cook constitutive equations for plastic flow stress and failure. The cutting tool is set as a rigid body fixed in space, while the workpiece is set as deformable, moving towards the cutting tool with a speed equal to the cutting speed. The model, taking into account both process parameters (cutting speed, depth of cut, etc.) and tool geometrical characteristics (rake angle, clearance angle), generates a number of KPIs (MRR, cutting forces, residual stress), thus allowing optimization of process parameters. The simulation results were validated through an experimental campaign relying upon a milling machine equipped with an accelerometer and an acoustic emissions sensor [31], also generating useful knowledge as regard surface roughness and tool wear correlation to process parameters.
Fig. 5 Stage 3 methodology

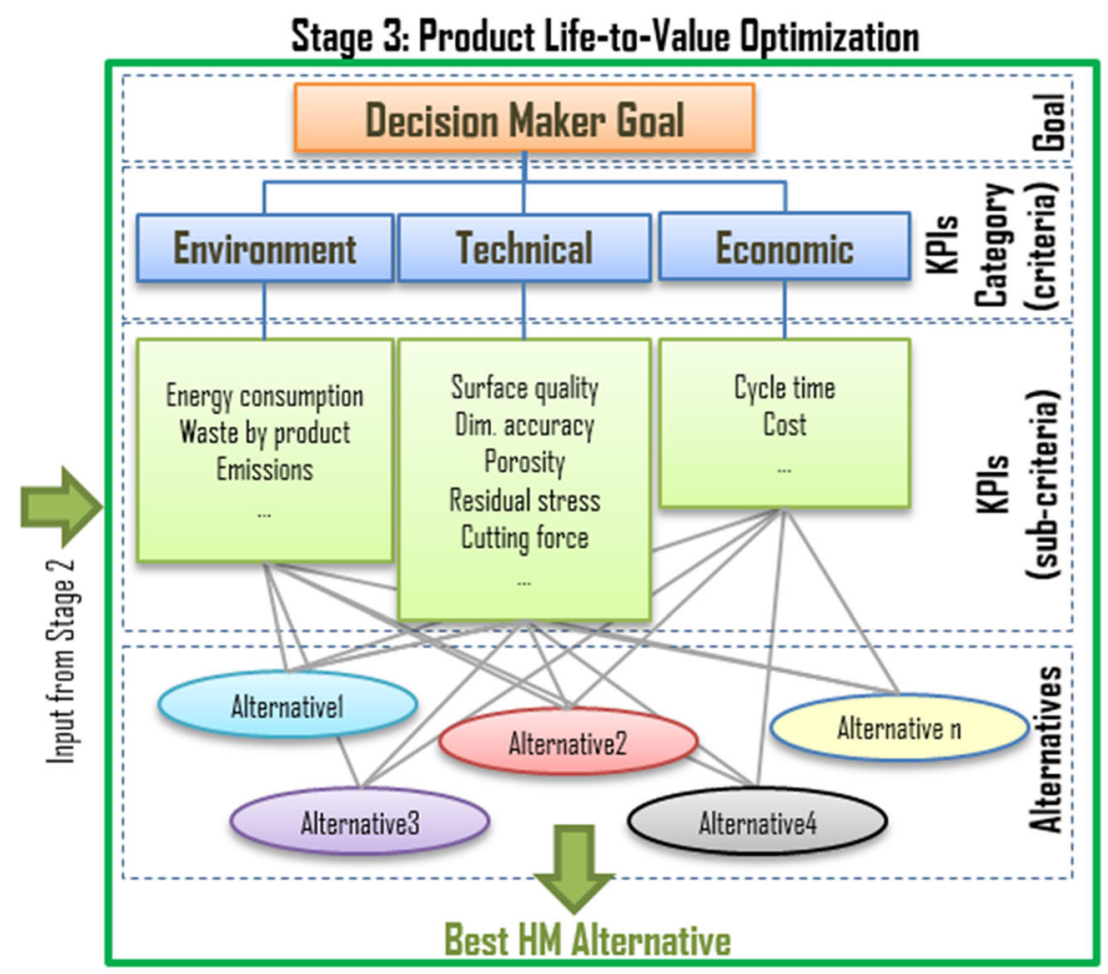



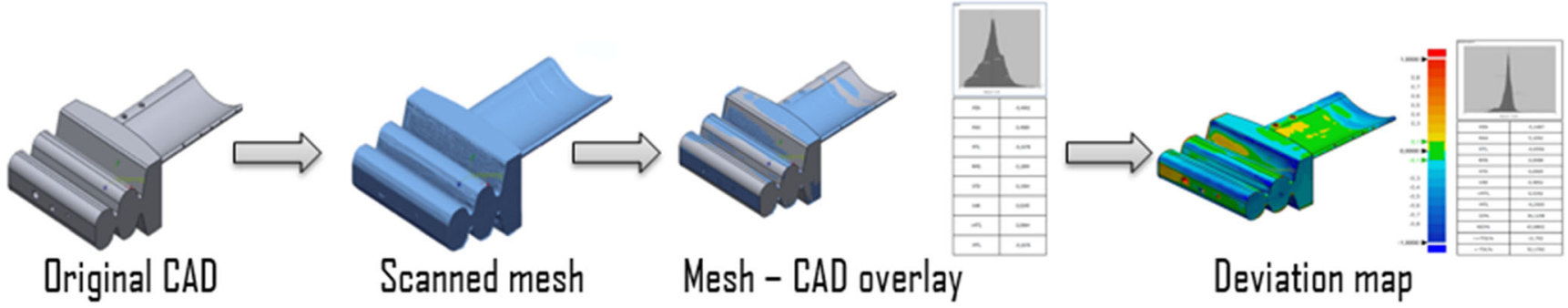

Fig. 6 Creation of the deviation map of the part

\subsection{Stage 3: Product life-to-value optimization}

In order to calculate the life-to-value performance score supporting the decision on the most suited hybrid process plan for part manufacturing the setup of the AHP method should be performed first. Between the decision maker's strategic goal and the process plan, alternatives reside the attributes of the decision problem such as the selection of the KPIs category as well as the specific KPIs under each category (Fig. 5). While considering part quality KPIs (technical pillar) as the most relevant, the performance of a manufacturing strategy can be measured against multiple KPIs which are very often contradictory (minimize cost vs. increase surface quality).

To execute the model both KPI category and KPIs (i.e. criteria and sub-criteria) must have associated weights and scores. Each implementation of the model has its own series of importance weights, elicited from expert knowledge, existing data, or simply expressing the preferences of the decision-maker. For a perfectly balanced perspective on the selection of the most adapted hybrid process plan, an equal weight of $33.3 \%$ can be assigned to each KPI category. A set of matrices representing the pairwise comparison is developed at every level of the hierarchy, assuming an element in the upper level is the governing element for those in the lower hierarchy. These comparisons yield square matrices of judgments. After the consistency test, serving to identify possible errors in expressing judgments, the local and global weights are calculated which represents the contribution of each criterion and sub-criteria to the strategic goal. In the final step, a ranking of all the alternatives will be performed based on the individual performance of every operation included in a process plan alternative with respect to the KPIs considered as well as the aggregation of these performances to one global score.

\section{Case study}

In order to validate the complete process chain design, an industrial use case involving a repair scenario of a $316 \mathrm{~L}$ Stainless Steel gas turbine blade is implemented. $316 \mathrm{~L}$ presents a significant interest for this work, as it is used in a wide range of applications where repair with hybrid manufacturing through additive manufacturing and milling would be highly beneficial. In principle, additive manufacturing introduces thermally induced stresses that can be alleviated using heat
Fig. 7 Process plan alternatives generated for the particular case study

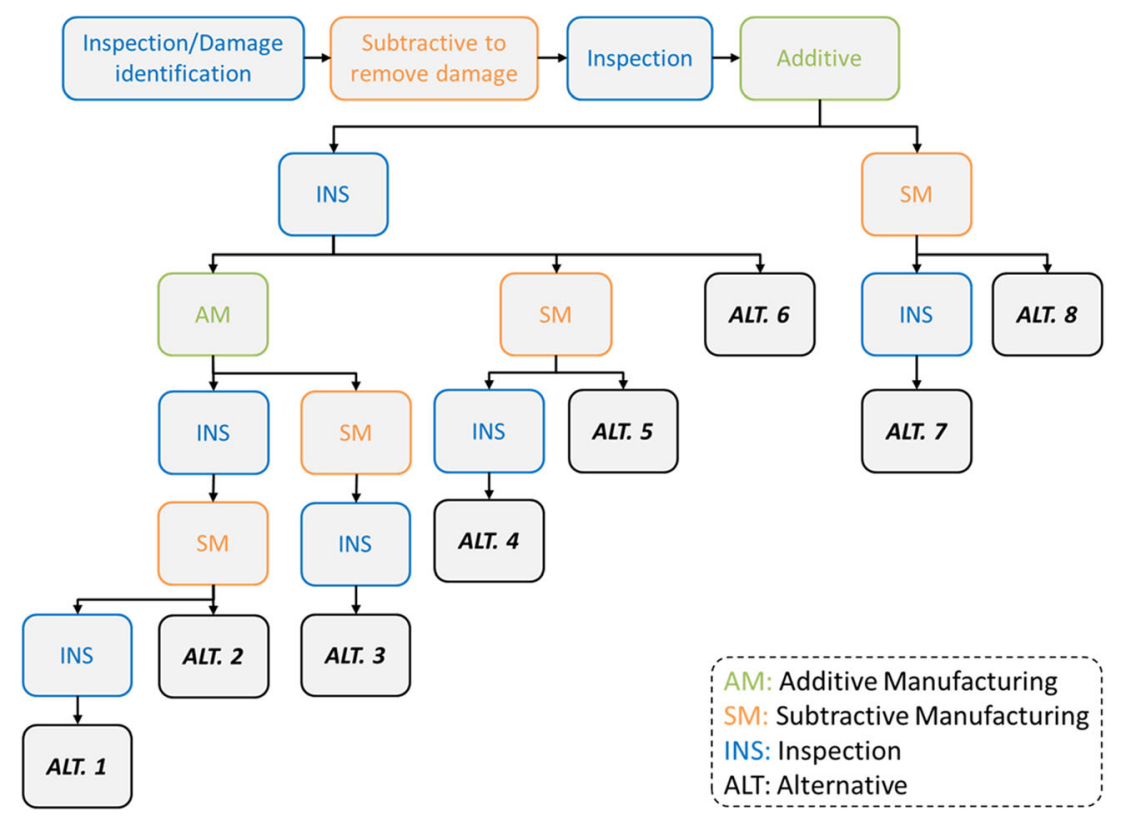


Table 1 Parameter sets for additive manufacturing

\begin{tabular}{|c|c|c|c|c|c|c|c|}
\hline \multicolumn{2}{|c|}{ Parameter set \# } & \multirow[t]{2}{*}{ KPI type } & \multirow{2}{*}{$\begin{array}{l}\text { SM1 } \\
10\end{array}$} & \multirow{2}{*}{$\begin{array}{c}\text { SM2 } \\
10\end{array}$} & \multirow{2}{*}{$\begin{array}{c}\text { SM3 } \\
10\end{array}$} & \multirow{2}{*}{$\begin{array}{l}\text { SM4 } \\
2\end{array}$} & \multirow{2}{*}{$\begin{array}{l}\text { SM5 } \\
2\end{array}$} \\
\hline Parameters & Tool diameter (mm) & & & & & & \\
\hline & Cutting speed (m/min) & & 120 & 160 & 190 & 157 & 188 \\
\hline & Feed per tooth $(\mathrm{mm})$ & & 0.025 & 0.03 & 0.017 & 0.0036 & 0.003 \\
\hline & Axial DoC (mm) & & 4 & 4 & 4 & 2 & 2 \\
\hline & Radial DoC (mm) & & 0.15 & 0.15 & 0.3 & 0.05 & 0.1 \\
\hline \multirow[t]{3}{*}{ KPIs } & Material removal rate $\left(\mathrm{mm}^{3} / \mathrm{min}\right)$ & Economic & 240 & 360 & 480 & 0.018 & 0.036 \\
\hline & $\begin{array}{l}\text { Expected surface roughness Ra } \\
\quad(\mu \mathrm{m})\end{array}$ & Technical & 0.68 & 1.78 & 3.78 & 0.42 & 6.59 \\
\hline & Expected tool life (min) & Economic & 13.5 & 5 & 3.5 & 9.5 & 12.6 \\
\hline
\end{tabular}

treatment. Although 316L cannot be heat treated, AM of 316L alloys has been successfully used in the past [32-37], even for repair purposes [38], and its fatigue life has been deemed satisfactory [39-41]. The processes used in this case are DLM, milling, and vision-based metrology, but additional processes could be considered as appropriate. As this is a repair scenario, the process chain started from an inspection operation, acquiring a point cloud of the pre-existing blade, followed by a comparison with the CAD file, and generation of a deviation map (Fig. 6). This allowed calculation of both the deviation of the real dimensions in comparison with the ideal situation, identification of the damaged area, and precise localization of the blade with respect to the machine frame for the subsequent operations.

The next step involved a subtractive operation to remove the damaged area. At this point, a number of alternative process plans/strategies are generated, as depicted in Fig. 7.

The process plan alternatives consist of different combinations and sequences of the available operations, based on the method presented in Section 3.1. The process parameters for each one of those operations are tailored to the specific conditions occurring from the presence of previous or subsequent operations on the specific process plan alternative. As an example, DLM process parameters can be optimized for deposition rates rather than for dimensional accuracy. This stems from the logic that the over-deposited volume, resulted after the DLM process, will be subsequently removed by the subtractive operation. Similarly, milling process parameters can be optimized for quality (minimum surface roughness) when a single finishing pass strategy is deployed, or two-parameter sets can be used when the volume of material to remove is higher; one parameter set for one or multiple rough milling pass(es) to remove the bulk of the material as fast as possible, followed by a finishing pass with process parameters optimized for quality.

To demonstrate the effectiveness of the method, three of the alternatives generated (Alt. 2, Alt. 5, and Alt. 7) are further analysed and evaluated. Each alternative uses not only a different sequence of operations but also different sets of process parameters for these operations. Two sets of process parameters are used for the AM operation, while three and two sets of parameters are used for the subtractive (side and face milling) operations respectively. These process parameter sets have been generated as a result of the second stage of the process planning framework and are presented in Tables 1 and 2, while their combination and process steps per alternative are presented on Table 3. The KPI values for the parameter sets have been acquired from the experimental campaigns that were run during stage 2 , in order to validate the process models and create the knowledge base for process optimization.

Four KPIs are examined: surface roughness (on top and side surfaces of the blade), total process time, tool life (both for the $10-\mathrm{mm}$ tool used for side milling, and the 2-mm tool used for face milling), and material waste. Pairwise comparisons as established in the AHP method are used to derive the
Table 2 Parameter sets for additive manufacturing

\begin{tabular}{lllll}
\hline Parameter Set \# & & KPI Type & AM1 & AM2 \\
\hline Parameters & Laser power $(\mathrm{W})$ & 700 & 200 \\
& Stand-off distance $(\mathrm{mm})$ & 10 & 10 \\
& Powder feed rate $(\mathrm{g} / \mathrm{s})$ & 0.042 & 0.042 \\
& Carrier gas flow rate $(\mathrm{L} / \mathrm{min})$ & 15 & 15 \\
& Scanning speed $(\mathrm{mm} / \mathrm{min})$ & & 700 & 200 \\
KPI & Specific energy $(\mathrm{J} / \mathrm{mm})$ & Environmental & 52.5 & 60 \\
\hline
\end{tabular}


Table 3 Analytic list of operations for each alternative

\begin{tabular}{|c|c|c|}
\hline \multicolumn{3}{|l|}{ Alternative 2} \\
\hline Operation & Process parameters set & Comments \\
\hline Inspection & - & Damage identification \\
\hline Subtractive manufacturing & SM3 & Damage removal: priority on high $\mathrm{MRR}$ \\
\hline Inspection & - & Update of 3D model \\
\hline Additive manufacturing (Contour) & AM2 & Deposition on damaged area: priority on contour accuracy \\
\hline Additive manufacturing (Infill) & AM1 & Deposition on damaged area: priority on high deposition rates \\
\hline Inspection & - & Check for AM defects \\
\hline Additive manufacturing & AM2 & Deposition on damaged area: priority on accuracy \\
\hline Inspection & - & Update of 3D model \\
\hline Subtractive manufacturing (Blade Walls) & SM1 & Finishing of the part: priority on low surface roughness \\
\hline Subtractive manufacturing (Blade Top) & SM4 & Finishing of the part: priority on low surface roughness \\
\hline \multicolumn{3}{|l|}{ Alternative 5} \\
\hline Operation & Process parameters set & Comments \\
\hline Inspection & - & Damage identification \\
\hline Subtractive manufacturing & SM3 & Damage removal: priority on high MRR \\
\hline Inspection & - & Update of 3D model \\
\hline Additive manufacturing & AM1 & Deposition on damaged area: priority on high deposition rates \\
\hline Inspection & - & Update of 3D model \\
\hline Subtractive manufacturing (Blade Walls) & SM2 & Finishing of the part: compromise between roughness and MRR \\
\hline Subtractive manufacturing (Blade Top) & SM4 & Finishing of the part: priority on low surface roughness \\
\hline \multicolumn{3}{|l|}{ Alternative 7} \\
\hline Operation & Process parameters set & Comments \\
\hline Inspection & - & Damage identification \\
\hline Subtractive manufacturing & SM3 & Damage removal: priority on high MRR \\
\hline Inspection & & Update of 3D model \\
\hline Additive manufacturing & AM1 & Deposition on damaged area: priority on high deposition rates \\
\hline Subtractive manufacturing (Blade wall roughing) & SM3 & Rough milling of over-deposited volume: Priority on high MRR \\
\hline $\begin{array}{l}\text { Subtractive manufacturing } \\
\text { (Blade wall finishing) }\end{array}$ & SM1 & Finishing of the part: priority on low surface roughness \\
\hline Subtractive manufacturing (Blade top roughing) & SM5 & Rough milling of over-deposited volume: Priority on high MRR \\
\hline Subtractive manufacturing (Blade top finishing) & SM4 & Finishing of the part: priority on low surface roughness \\
\hline Inspection & - & Final dimensional inspection \\
\hline
\end{tabular}

resulting priorities, with a consistency ratio of $5 \%$. The KPIs (calculated for every alternative, considering the complete process plan), priorities, and raw values per alternative are presented in Table 4.

Raw KPI values are subsequently normalized; the normalized calculation for each KPI is between the value 0 , for the worst alternative, and 1 for the best alternative. The normalized values multiplied by the priority result in a score, total scores are calculated per alternative, and alternatives ranked accordingly. The outcome of this process can be seen in Table 5.
Following the selection of the optimal process plan alternative (Alt. 2), the part program is simulated for collisions and then loaded on the machine controller. The final outcome can be seen in Fig. 8.

The results are further discussed in Section 5.

\section{Discussion}

Applying the proposed method on an industrial case study of repairing a gas turbine blade, it is evident that Alt. 2 is the
Table 4 Process planning alternatives KPIs

\begin{tabular}{lrllll}
\hline KPI & KPI type & Priority & Alt. 2 & Alt. 5 & Alt. 7 \\
\hline Surface roughness (top) & Technical & $31.7 \%$ & 0.42 & 0.42 & 0.42 \\
Surface roughness (wall) & Technical & $31.7 \%$ & 0.68 & 1.78 & 0.68 \\
Process time (s) & Economic & $24.7 \%$ & 1090 & 1074 & 1232 \\
Tool wear (top) & Economic & $3.7 \%$ & $98.6 \%$ & $98.6 \%$ & $87.5 \%$ \\
Tool wear (wall) & Economic & $3.7 \%$ & $6.1 \%$ & $11 \%$ & $29.4 \%$ \\
Material waste & Environmental & $4.5 \%$ & 196.2 & 192.2 & 588.3 \\
\hline
\end{tabular}


Table 5 Process planning alternatives score

\begin{tabular}{lllll}
\hline KPI & KPI type & Alt. 2 & Alt. 5 & Alt. 7 \\
\hline Surface roughness (top) & Technical & 0.317 & 0.317 & 0.317 \\
Surface roughness (wall) & Technical & 0.317 & 0 & 0.317 \\
Process time (s) & Economic & 0.222 & 0.247 & 0 \\
Tool Wear (top) & Economic & 0 & 0 & 0.037 \\
Tool Wear (wall) & Economic & 0.037 & 0.029 & 0 \\
Material waste & Environmental & 0.044 & 0.045 & 0 \\
Total score & & 0.937 & 0.638 & 0.671 \\
\hline
\end{tabular}

The emphasized text denotes the highest total score of all alternatives

preferred one among the three alternative process plans that have been chosen for investigation (Table 5). In this case, better performance of Alt. 2 can be attributed mainly to the use of more intermediate inspection cycles between the subsequent AM steps. This strategy enables more effective exploitation of the AM process, preserving a stable material growth, thus requiring less post-processing with milling, which in turn decreases the overall process time and material waste. It is worth mentioning that this is only true taking into account the examined sets of process parameters and their impact in the performance on the separate processes, as well as for the specific relative importance of the different KPIs. For example, if the time required for intermediate inspection steps is dramatically increased, the preferred alternative might change. Similarly, if process time was prioritized, Alt. 5 would most probably be the new preferred strategy. Nevertheless, the method itself accounts for such changes, as it is able to reevaluate the alternative process plans as needed. In addition, the user can modify the relative weight of each KPI, which will result in a different evaluation of the alternatives.

Moreover, it is observed that Alt. 5 and Alt. 7 are close to each other in terms of overall performance, despite they comprise different individual process steps, parameters, and subsequent performance in each individual KPI. This makes clear that more than one alternative can display similar performance, which can render the process of selecting one quite trivial. As such, the proposed method is a useful tool in aiding the user to have a clear overview of the potential options, and

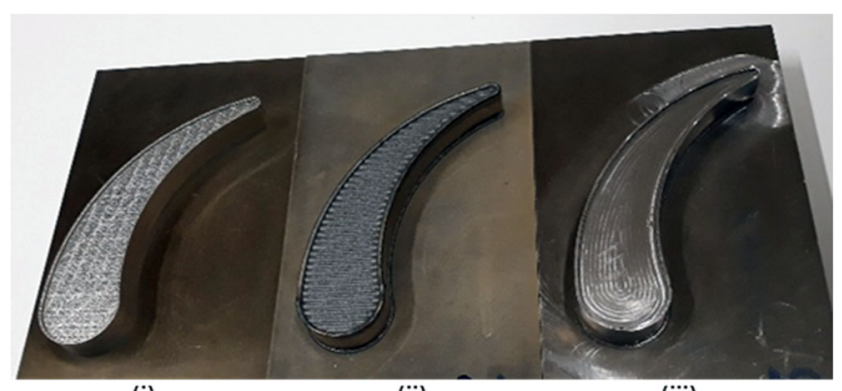

(i)

(ii)

(iii)

Fig. 8 Gas turbine blade samples used for validation. (i) Damaged part, (ii) part after deposition, and (iii) part after final milling thus enabling shifting to another alternative process plan if new constraints come up (change in priorities, machine availability, increase in the cost of a particular resource, etc.).

\section{Conclusions}

The paper introduces a novel process planning approach to support hybrid process chain design, aiming to optimize product life-to-value ratio. The method is based upon the effective generation of hybrid process plan alternatives, utilizing simulation and experimentation knowledge (or a combination thereof) as the enabler of a multi-criteria evaluation process, based on the exact user requirements.

Applying the method in the repair scenario of a gas turbine blade, it is evident that the same outcome in terms of part quality (surface roughness in this particular case) is attainable through multiple hybrid process chain alternatives. However, the total time required, tool wear, and other KPIs may differ, based on the alternative process plan deployed. The proposed method is able to capture and appreciate these differences, leading to a consistent ranking of the potential alternatives, while also making explicit the benefits and drawbacks of each process plan alternative in a consolidated form. These data can be subsequently used in multiple ways: from planning the overall company production, managing inventory (tools, raw materials), to modify the design of the actual part for hybrid manufacturing.

Suggestions for future work include the integration of the developments in a single software tool that will enable the time-efficient generation of effective hybrid process chains. In addition, suitability (both from a technical and an economic perspective) and applicability of hybrid process chains should be evaluated, based on the exact material, component, and intended application, as well as on industry standards. Finally, there is a need to evaluate the impact of a hybrid process chain in the structural integrity and subsequently in relevant standards for repair of safety-critical structures.

Funding This research has been partially funded by EIT Manufacturing, under the 2020 activity "FlexHyMan: A Flexible Hybrid Manufacturing system", A20117.

Open Access This article is licensed under a Creative Commons Attribution 4.0 International License, which permits use, sharing, adaptation, distribution and reproduction in any medium or format, as long as you give appropriate credit to the original author(s) and the source, provide a link to the Creative Commons licence, and indicate if changes were made. The images or other third party material in this article are included in the article's Creative Commons licence, unless indicated otherwise in a credit line to the material. If material is not included in the article's Creative Commons licence and your intended use is not permitted by statutory regulation or exceeds the permitted use, you will need to obtain permission directly from the copyright holder. To view a copy of this licence, visit http://creativecommons.org/licenses/by/4.0/. 


\section{References}

1. Chryssolouris G (2006) Manufacturing systems: theory and practice, 2nd edn. Springer, Verlag

2. Al-wswasi M, Ivanov A, Makatsoris H (2018) A survey on smart automated computer-aided process planning (ACAPP) techniques. Int J Adv Manuf Technol 97:809-832

3. Ford S, Despeisse M (2016) Additive manufacturing and sustainability: an exploratory study of the advantages and challenges. J Clean Prod 137:1573-1587

4. Tabernero I, Paskual A, Álvarez P, Suárez A (2018) Study on arc welding processes for high deposition rate additive manufacturing. Procedia CIRP 68:358-362

5. Bikas H, Lianos AK, Stavropoulos P (2019) A design framework for additive manufacturing. Int J Adv Manuf Technol 103:37693783

6. Khan SZ, Masood S, Cottam R (2017) Mechanical properties of a novel plymetal manufactured by laser-assisted direct metal deposition. Int J Adv Manuf Technol 91:1839-1849

7. Wohlers Terry T, Campbell Ian, Diegel Olaf, Huff Ray, Kowen Joseph, Wohlers Report (2019) 369-page publication, Wohlers Associates, Inc., March 2019

8. Zhu Z, Dhokia V, Newman ST (2017) A novel decision-making logic for hybrid manufacture of prismatic components based on existing parts. J Intell Manuf 28:131-148

9. Vayre B, Vignat F, Villeneuve F (2012) Metallic additive manufacturing: state-of-the-art review and prospects, Mechanics \& Industry. 13(2):89-96

10. Soshi M, Ring J, Young C, Oda Y, Mori M, Masahiko (2017) Innovative grid molding and cooling using an additive and subtractive hybrid CNC machine tool. In: CIRP Annals - Manufacturing Technology, p 66

11. Chong L, Ramakrishna S, Singh S (2018) A review of digital manufacturing-based hybrid additive manufacturing processes. Int J Adv Manuf Technol 95:2281-2300

12. Nau B, Roderburg A, Klocke F (2011) Ramp-up of hybrid manufacturing technologies. CIRP J Manuf Sci Technol 4(3): 313-316

13. Kopf R, Gottwald J, Jacob A, Brandt M, Lanza G (2018) Costoriented planning of equipment for selective laser melting (SLM) in production lines. CIRP Ann 67(1):471-474

14. ElMaraghy H, Moussa M (2019) Optimal platform design and process plan for managing variety using hybrid manufacturing. CIRP Ann 68(1):443-446

15. Priarone PC, Campatelli G, Montevecchi F, Venturini G, Settineri L (2019) A modelling framework for comparing the environmental and economic performance of WAAM-based integrated manufacturing and machining. CIRP Ann 68(1):37-40

16. Basinger KL, Keough CB, Webster CE, Wysk RA, Martin TM, Harrysson OL (2018) Development of a modular computer-aided process planning (CAPP) system for additive-subtractive hybrid manufacturing of pockets, holes, and flat surfaces. Int J Adv Manuf Technol 96:2407-2420

17. Liu C, Li Y, Jiang S, Li Z, Xu K (2019) A sequence planning method for five-axis hybrid manufacturing of complex structural parts. In: Proceedings of the Institution of Mechanical Engineers, Part B: Journal of Engineering Manufacture, pp 1-10

18. Mazzucato F, Aversa A, Doglione R, Biamino S, Valente A, Lombardi M (2019) Influence of process parameters and deposition strategy on laser metal deposition of 316L powder. Metals 9:11

19. Bikas H, Koutsoukos S, Stavropoulos P (2019) A decision support method for evaluation and process selection of Additive Manufacturing. Procedia CIRP 81:1107-1112
20. Behandish M, Nelaturi S, de Kleer J (2018) Automated process planning for hybrid manufacturing. Comput Aided Des 102:115127

21. Luo X, Li Y, Frank MC (2013) A finishing cutter selection algorithm for additive/subtractive rapid pattern manufacturing. Int $\mathrm{J}$ Adv Manuf Technol 69:2041-2053

22. Zhu Z, Dhokia V, Newman ST (2013) The development of a novel process planning algorithm for an unconstrained hybrid manufacturing process. J Manuf Process 15:404-413

23. Siemens NX, available online (March 2020): https://www.plm. automation.siemens.com/global/en/products/manufacturingplanning/additive-manufacturing.html. Accessed 16 Mar 2020

24. O. Avram, A. Valente, C. Fellows (2018), Adaptive CAx chain for hybrid manufacturing, Proceedings of Direct Digital Manufacturing Conference, pp. 239-245, Stuttgart, Germany

25. Karagiannis S, Stavropoulos P, Ziogas C, Kechagias J (2014) Prediction of surface roughness magnitude in computer numerical controlled end milling processes using neural networks, by considering a set of influence parameters: An aluminum alloy 5083 case study. Proc IMechE B J Eng Manuf 228:233-244

26. Stavropoulos P, Papacharalampopoulos A, Vasiliadis E, Chryssolouris G (2016) Tool wear predictability estimation in milling based on multi-sensorial data. Int J Adv Manuf Technol 82(1): $509-521$

27. Goepel KD (2018) Implementation of an Online Software Tool for the Analytic Hierarchy Process (AHP-OS). Int J Analytic Hierar Proc 10(3):469-487

28. Bikas H, Stavropoulos P, Chryssolouris G (2016) Additive manufacturing methods and modelling approaches: a critical review. Int J Adv Manuf Technol 83(1):389-405

29. Picasso M, Marsden CF, Wagniere JD (1994) A simple but realistic model for laser cladding. MMTB 25:281-291

30. Ratchev S, Liu S, Huang W, Becker AA (2007) Machining simulation and system integration combining FE analysis and cutting mechanics modelling. Int J Adv Manuf Technol 35:55-65

31. Stavropoulos P, Stournaras A, Chryssolouris G (2008) On the design of a monitoring system for desktop micro-milling machines , (ICMR 08), 6th International Conference on Manufacturing Research, Uxbridge, UK, 483-491

32. Azinpour E, Darabi R, de Sa JC, Santos A, Hodek J, Dzugan J (2020) Fracture analysis in directed energy deposition (DED) manufactured 316L stainless steel using a phase-field approach. In: Finite Elements in Analysis and Design, vol 177. https://doi. org/10.1016/j.finel.2020.103417

33. Zheng B, Haley JC, Yang N, Yee J, Terrassa KW, Zhou Y, Lavernia EJ, Schoenung JM (2019) On the evolution of microstructure and defect control in 316L SS components fabricated via directed energy deposition. In: Materials Science and Engineering: A, vol 764. https://doi.org/10.1016/j.msea.2019.138243

34. Saboori A, Piscopo G, Lai M, Salmi A, Biamino S (2020) An investigation on the effect of deposition pattern on the microstructure, mechanical properties and residual stress of 316L produced by Directed Energy Deposition. In: Materials Science and Engineering: A, vol 780. https://doi.org/10.1016/j.msea.2020. 139179

35. Feenstra DR, Cruz V, Gao X, Molotnikov A, Birbilis N (2020) Effect of build height on the properties of large format stainless steel 316L fabricated via directed energy deposition. In: Effect of build height on the properties of large format stainless steel 316L fabricated via directed energy deposition, Additive Manufacturing, Volume 34. https://doi.org/10.1016/j.addma.2020.101205

36. Kersten S, Praniewicz M, Kurfess T, Saldana C (2020) Build Orientation Effects on Mechanical Properties of $316 \mathrm{SS}$ Components Produced by Directed Energy Deposition. Procedia Manuf 48:730-736. https://doi.org/10.1016/j.promfg.2020.05.106 
37. Kim D-K, Woo W, Kim E-Y, Choi S-H (2019) Microstructure and mechanical characteristics of multi-layered materials composed of 316L stainless steel and ferritic steel produced by direct energy deposition. J Alloys Compd 774:896-907. https://doi.org/10. 1016/j.jallcom.2018.09.390

38. Wook Jin O, Lee WJ, Kim MS, Jeon JB, Shim DS (2019) Repairing additive-manufactured $316 \mathrm{~L}$ stainless steel using direct energy deposition. Opt Laser Technol 117:6-17. https://doi.org/10.1016/j. optlastec.2019.04.012

39. Shrestha R, Simsiriwong J, Shamsaei N (2019) Fatigue behavior of additive manufactured 316L stainless steel parts: Effects of layer orientation and surface roughness. Addit Manuf 28:23-38. https:// doi.org/10.1016/j.addma.2019.04.011
40. Balit Y, Joly L-R, Szmytka F, Durbecq S, Charkaluk E, Constantinescu A (2020) Self-heating behavior during cyclic loadings of $316 \mathrm{~L}$ stainless steel specimens manufactured or repaired by Directed Energy Deposition. In: Materials Science and Engineering: A, vol 786. https://doi.org/10.1016/j.msea.2020.139476

41. Smith TR, Sugar JD, Schoenung JM, Marchi CS (2019) Relationship between manufacturing defects and fatigue properties of additive manufactured austenitic stainless steel. In: Materials Science and Engineering: A, p 765. https://doi.org/10.1016/j. msea.2019.138268

Publisher's note Springer Nature remains neutral with regard to jurisdictional claims in published maps and institutional affiliations. 